Filol. Linguíst. Port., São Paulo, v. 17, n. 2, p. 495-508, jul./dez. 2015

http://dx.doi.org/10.11606/issn.2176-9419.v17i2p495-508

\title{
O processo de alfabetização e a produção do sentido no discurso escrito
}

\author{
The literacy process and the production of \\ sense in written speech
}

\author{
Cecilia M. A. Goulart* \\ Universidade Federal Fluminense, Niterói, Rio de Janeiro, Brasil
}

\begin{abstract}
Resumo: O estudo tem como objetivo compreender aspectos do processo de alfabetização infantil por meio da análise de indícios da reflexão sobre a escrita e a linguagem por parte de uma criança. Busca-se evidenciar a presença do sujeito na linguagem, no contexto da opacidade da realidade e da linguagem, pela análise dos modos de constituição de um texto escrito. Selecionamos, por sua originalidade, o texto escrito de uma menina de 5 anos, parte do banco de dados do grupo de pesquisa Linguagem, cultura e processos educativos/CNPq. Aspectos da teoria da enunciação de Bakhtin, da constituição da escrita e da relação entre oralidade e letramento são vetores da base teórico-metodológica. $\mathrm{O}$ saber indiciário utilizado tem como base o método de conhecimento cuja força está na observação do pormenor revelador, do detalhe. $\mathrm{Na}$ análise do texto da menina, observamos como diferentes sistemas representacionais convivem em seu esforço para significar por escrito. Sistemas orientados por princípios organizacionais distintos são utilizados com funçôes variadas, e, por vezes, apresentam instabilidades no uso da mesma função. Os diferentes signos são orientados para o interlocutor, o auditório social (Bakhtin, 1998). Na análise, sobressai a seleção de palavras dos enunciados, realizada a partir das intençôes que presidem o seu todo, e, na perspectiva da tensão interna que existe em qualquer signo, de acordo com Bakhtin. Aprender a escrever abrange conhecer o princípio alfabético da escrita no interior de complexa trama de outros conhecimentos envolvida na produção de linguagem com valor
\end{abstract}

Professora do Departamento Sociedade, educação e conhecimento da Faculdade de Educação da Universidade Federal Fluminense, Niterói, Rio de Janeiro, Brasil, goulartcecilia@uol.com.br. 
social. É importante entender a aprendizagem da escrita como um processo marcado por instabilidades e estabilidades, e as crianças como pessoas capazes de aprender complexamente.

Palavras-chave: Alfabetização. Discurso escrito. Paradigma indiciário.

Abstract: The study aims at understanding aspects of children's literacy process based on the analysis of traces of a child's thought processes concerning the production of a written text. The aim is to highlight the presence of the subject in language, considering the opacity of reality and language. A written text of a 5 year-old child was selected from the database of our research group, due to its originality of construction. Theoretical and methodological guidelines make use of aspects of Bakhtin's enunciation theory, of the history of writing and of the relation between oral and written language. The use of indicial knowledge is based on the method of knowledge whose strength is grounded in the observation of revealing details. The analysis of the child's text shows how different representational systems coexist in her efforts to convey meaning by writing. Systems governed by distinct organizational principles are used with varying functions; the same function may sometimes present instabilities in its uses. Different signs are used considering the interlocutor and the social audience (Bakhtin, 1998). These findings support the view that learning to write involves knowing the alphabetical principle of language as well as the complex web of other knowledge bearing on the production of language having social value. It is important to understand learning of writing as a process presenting instabilities and stabilities, and children as persons who are capable of learning in complex ways.

Keywords: Learning to read and write. Written discourse. Indicial knowledge.

\section{CONTEXTUALIZANDO O TEMA DO ARTIGO}

No Brasil temos um histórico de produção do que chamo de dislexia sígnica em uma parcela imensa da população brasileira. Por tal denominação entendo a aprendizagem da escrita que não modifica, ou modifica muito pouco, a condição das pessoas de pertencimento à sociedade letrada (Soares, 1998, p. 19), apesar de serem consideradas alfabetizadas pela escola. Estas crianças, jovens e adultos não utilizam a escrita como forma de ampliar a leitura do mundo. O que se observa é que a apresentação pela escola da linguagem escrita como um simulacro, de modo geral por meio de textos acartilhados, revela um ensino isolado das tensões discursivas e da historicidade, existentes em qualquer processo e qualquer texto.

Goulart, C.M.A. O processo de alfabetização e a produção do sentido no discurso escrito... 
A reflexão de Calvino sobre a literatura (Calvino, 1990, p. 27) pode, no meu entender, iluminar a compreensão do campo do ensino da leitura e da escrita. Pensando neste campo no Brasil, também duas vocações têm-se confrontado historicamente. Uma tende a fazer da linguagem um elemento sem peso; pode ser associada ao que, criticamente, Street $(1983$; 2003) caracteriza como modelo autônomo de letramento. Neste modelo, é priorizada a análise da língua, subordinando seus falantes e sua existência social ao estudo de características do sistema linguístico. A outra vocação tende a dar peso à linguagem, interpretando-a como criação humana e social, com espessura, concretude, impregnada de valores contraditórios, ideológicos, marcados em sua opacidade e indeterminação. Esta subordina a língua à dimensão política dos discursos, dos textos, dos enunciados.

Nosso estudo, identificando-se com a segunda vocação, considera que as crianças vivem ativa e interativamente os processos de ensino-aprendizagem da escrita, criando formas de compreender como a escrita produz sentido socialmente. Neste contexto, então, é que será analisado o texto escrito por uma menina de 5 anos, parte do banco de dados do grupo de pesquisa Linguagem, cultura e práticas educativas/CNPq. O texto foi selecionado levando-se em conta a originalidade de sua construção, tornando-o emblemático de caminhos e possibilidades do pensamento infantil no processo de aprendizagem da escrita de textos. Constitui-se assim em relevante espaço de reflexão, contribuindo para ampliar e aprofundar a discussão sobre os processos de aprendizagem das crianças.

$\mathrm{Na}$ direção apontada, este artigo tem como objetivo compreender aspectos do processo de alfabetização infantil, por meio da análise de indícios de reflexão da criança sobre aspectos constitutivos da escrita. Como a criança responde às demandas que a produção do texto escrito apresenta? Buscamos evidenciar a presença da criança no discurso que produz, procurando desvendar no contexto da opacidade da realidade e da linguagem, marcas do processo de constituição do discurso escrito.

Aspectos da teoria da enunciação de Bakhtin, da história da escrita e da relação entre oralidade e letramento se constituem em vetores da base teórico-metodológica. Nosso horizonte de trabalho é, considerando características de processos de aprendizagem, contribuir para uma teoria do ensino da escrita que tenha como eixo a relaçáo entre os discursos produzidos fora da escola e os produzidos dentro dela, em sala de aula, tanto orais quanto escritos. A escrita nos identifica como integrantes da cultura letrada, por meio de documentos, por exemplo, regulando nossa existência jurídica, entre outras funçóes e de variados modos. Além disso, o fenômeno do letramento é associado não somente às práticas 
sociais escritas, mas também às práticas sociais orais, mesmo que materialmente a escrita não esteja presente. $\mathrm{E}$ do mesmo jeito afeta aqueles que não leem e não escrevem, já que vivemos num mundo em que a escrita é um forte marcador social, obrigatoriamente presente na vida de todos desde a certidão de nascimento, que nos credencia para a existência civil.

A investigação se desenvolve por meio da análise de indícios de reflexão da menina, ao procurar solucionar as demandas que a produçấo escrita do texto apresenta. O saber indiciário tem como base o método de conhecimento cuja força está na observação do pormenor revelador, mais do que na dedução (Ginzburg, 1989, p. 156). No caso da aprendizagem da escrita, os dados apresentam, de acordo com Abaurre (1996, p. 47), "marcas de uma situação de grande e natural instabilidade. [...] Dada certa plasticidade natural da linguagem, nada mais natural, também, que essa plasticidade adquira maior visibilidade nas situaçóes-limite em que a linguagem se constitui em objeto de evidente manipulaçáo”.

Visamos a ultrapassar a explicação dos dados que somente se baseie na descrição da língua e do sistema - sem negá-la - para estudar os modos como os sujeitos se esforçam para dar sentido a seus textos, aprendendo como se organizam o discurso escrito, como novas linguagens sociais, novas formas de apreensão da realidade e novas formas de ação social. Considerando nosso objeto de estudo, para identificar e compreender indícios do que buscamos, transitamos no plano da língua para fortalecer o plano do discurso, buscando marcas coletivas e singulares nos processos de produção da escrita que se constrói por meio dos discursos de outros. Com base em Brait (2006) e Sobral (2007), seguiremos o percurso de análise que contempla a descrição, a análise e a interpretação do material selecionado, deixando que "os discursos revelem sua forma de produzir sentido" (Brait, 2006, p. 24).

\section{CULTURA ESCRITA, ESCRITA E ESCOLARIZAÇÃO DA ESCRITA}

A partir do século XVIII e principalmente no século XX, os livros inundaram o mundo e a escrita alfabética passou a gozar de grande prestígio, como nos informa Cagliari (2007). A escrita alfabética, associada de modo forte à cultura ocidental, tem organizado esta cultura, criando sistemas de valores e hierarquias, cujos significados atravessam a vida social de variadas maneiras, inclusive daqueles que náo têm o cotidiano vinculado ou dependente da escrita de uma forma direta. Por meio principalmente de leis, normas e outros dispositivos regulatórios, muitas vezes simbólicos, estamos todos submetidos a um mundo que se construiu com a escrita. Como afirma o autor, "quanto mais se produziu em termos de uso da

Goulart, C.M.A. O processo de alfabetizaçáo e a produçáo do sentido no discurso escrito... 
escrita alfabética, mais apareceram formas ideográficas no Ocidente. Basta abrir um jornal para se constatar isso" (Cagliari, 2007, p. 2).

Outro viés da cultura escrita investigado é o viés da materialidade e da textualidade dos discursos (Goulart, 2005; 2007; 2010). Neste viés, a noção de linguagens sociais (Bakhtin, 1998, p. 96-101, especialmente) é o eixo para a reflexão sobre diferentes formas de estruturação dos saberes, em discursos produzidos em diferentes esferas e instâncias sociais. Embora próxima da noção de gêneros do discurso, que estruturam nossos dizeres (Amorim, 2000), a noção de linguagens sociais não se confunde com ela. De diferentes modos, portanto, os gêneros do discurso e as linguagens sociais são modos de apreender a realidade.

Como a cultura escrita se escolariza? Escolarizar a cultura escrita é contextualizá-la para fins formais de ensinar e aprender. De acordo com Soares (1999), analisando o tema da escolarização da literatura infantil, a escolarização é um "processo inevitável, porque é da essência mesma da escola, é o processo que a institui e que a constitui" (Soares, 1999, p. 21). Soares sublinha que a escolarização inadequada pode ocorrer não só com a literatura, mas também com outros conhecimentos, quando transformados em saberes escolares. Considerando que escolarizar a cultura escrita é contextualizá-la para fins formais de ensinar e aprender, que caminhos tomar para ensinar a ler e a escrever?

A direção tradicional do estudo e da prática da alfabetização se caracteriza por grande controle da produção escrita da criança, já que as unidades linguísticas são apresentadas de forma gradual, tentando conduzir o processo da criança. Assim, ficam obscurecidas as reflexóes das crianças, além do discurso e suas condiçôes sociais de produção, deixando de lado inúmeros conhecimentos envolvidos na produção escrita. Se, por um lado, compreendemos o princípio alfabético como um conhecimento essencial à aprendizagem da escrita, por outro, sabemos que ele não é suficiente.

As formas como o discurso escrito pode se organizar estão relacionadas aos modos valorativos como a escrita organiza a sociedade e por ela é organizada. Relacionam-se também à materialidade das práticas culturais, no sentido político da alfabetização, considerando tanto os microaspectos da escrita quanto os macroaspectos, que situam as funções sociais da escrita.

O intervalo que separa palavras, que ordena a segmentação de palavras no texto, por exemplo, longe de se constituir um nada no texto, faz parte de sua semântica, sua sintaxe. Muitos fatores determinam os espaços entre as palavras, estas entidades linguísticas tão polimórficas e polifônicas, permitindo variadas formas de relação. Crianças e adultos mostram perceber a gama de possibilidades (morfo) 
sintáticas quando elaboram escritas como: "E en ventou o arcoi-res do céu" ou "em-pregada" (Corrêa, 1990, p. 33). Na profusão de possibilidades de sentido, as letras também entram em cena socialmente, desafiando a compreensão da escrita alfabética de origem fonético-fonológica (ou será ideográfica?): DNA, ETC, LSD, PS, SOS - sons ou imagens? Trata-se de dados que evidenciam o sujeito em ação na linguagem, procurando no processo de aprender, compreender como a escrita se organiza.

$\mathrm{Na}$ complexidade dos processos de aprendizagem, muitos conhecimentos, observaçóes e percepçóes são postos em circulação para que se solucionem os problemas que a elaboração de textos escritos apresenta. Crianças, jovens e adultos que estão na escola se constituem no interior de muitas redes de conhecimentos que interagem com a rede de conhecimento escolar. Como a escrita é aprendida em contextos sociais táo semiotizados?

Halliday (2004), em abordagem funcionalista, investiga processos de aprendizagem da fala e os concebe em perspectiva sócio-semiótica que implica a síntese de três modos de interpretação: a) da língua no contexto do sistema social; b) da língua como o aspecto de uma semiótica mais geral; e c) do sistema social como um sistema semiótico. Para o autor, uma criança que está aprendendo uma língua está aprendendo como significar. Conforme a criança constrói seu próprio potencial de significação na língua, está construindo uma semiótica social para ela mesma. Ela desenvolve estratégias semióticas de tal forma que pode utilizar seu sentido potencial enquanto o está construindo e construí-lo enquanto o utiliza. Tal compreensão encontra eco de modo forte em pesquisas anteriores sobre o processo de alfabetização.

Motivados para delinear uma abordagem discursiva dos processos de aprendizagem da escrita, nosso desafio é articular o estudo de Halliday à concepção de linguagem de Bakhtin. Entendemos a possibilidade de articulação quando Bakhtin afirma que é por meio da encarnação material em signos, semioticamente, que o ser humano se humaniza, constitui-se em sujeito social. A perspectiva filosófica de seu trabalho nos leva a compreender que apreender um objeto de estudo é aproximar o novo signo de outros signos já conhecidos, compreendendo-o valorativamente. Além disso, o autor também afirma que constituímos nossa palavra na tensão com a palavra alheia, na hibridização de linguagens, de valores. Consideramos a palavra, o texto, primeiramente na direção exterioridade-interioridade, priorizando a produção do discurso e não a língua, a constituição do sistema.

De acordo com o observado em outros estudos (Pacheco, 1992; 1997), o conhecimento do discurso escrito vai-se construindo pelo agenciamento de 
estratégias semióticas diversas por crianças, jovens e adultos. Estas estratégias parecem se organizar como uma arquitetura semiótica móvel, instável e aberta que vai sendo construída e modificada, a partir da realidade social, em função da definição de pertinência ao sistema, mas também da intencionalidade do autor e de novas necessidades do dizer. A arquitetura então se faz e desfaz no processo de aprendizagem, ao se administrarem as soluçóes a serem dadas em resposta às demandas enunciativas, sempre renovadas, que surgem no processo de interlocução. Conforme os alunos vão se tornando escritores experientes suplantam alguns problemas e reconhecem outros, ligados às convençóes gráficas e ortográficas (convençôes sociais) e também a linguagens sociais mais complexas a que vão tendo acesso nos processos escolares e outros.

As estratégias são encaradas como procedimentos heurísticos, como movimentos intelectuais, para lidar com as demandas que uma situação objetiva de aprendizagem implica. As experiências sociais dos sujeitos, a organização formal da escrita e seu uso social são estruturantes da aprendizagem, ao funcionarem como organizadores de probabilidades para a construção de estratégias pelo sujeito. Como o objeto e o sujeito vão-se transformando, no processo de aprendizagem que se constitui no interior de relaçóes discursivas, orais e escritas, as estratégias também devem ser redesenhadas, em função da organização de esferas de necessidades diferentes (Pacheco, 1997).

\section{ANÁLISE DO TEXTO DE MARIA: QUE CONHECIMENTOS SE INTERPÓEM NO PROCESSO DE APRENDIZAGEM DO DISCURSO ESCRITO?}

O texto a seguir, objeto de nossa análise, foi elaborado por uma menina de 5 anos, Maria (nome fictício), em uma escola privada, dirigida por freiras, portanto de orientação católica. A escola é conhecida no Rio de Janeiro por desenvolver uma proposta pedagógica considerada progressista. O texto foi produzido como conclusão de um projeto pedagógico que teve como ponto de partida o filme $O s$ dinossauros. A professora solicitou que as crianças registrassem o que haviam aprendido com o projeto realizado. A enunciação da palavra registro abre possibilidades de conduzir as crianças para diferentes formas de expressão, inclusive a escrita. 


\section{ESTORIAS DO PNSADO}

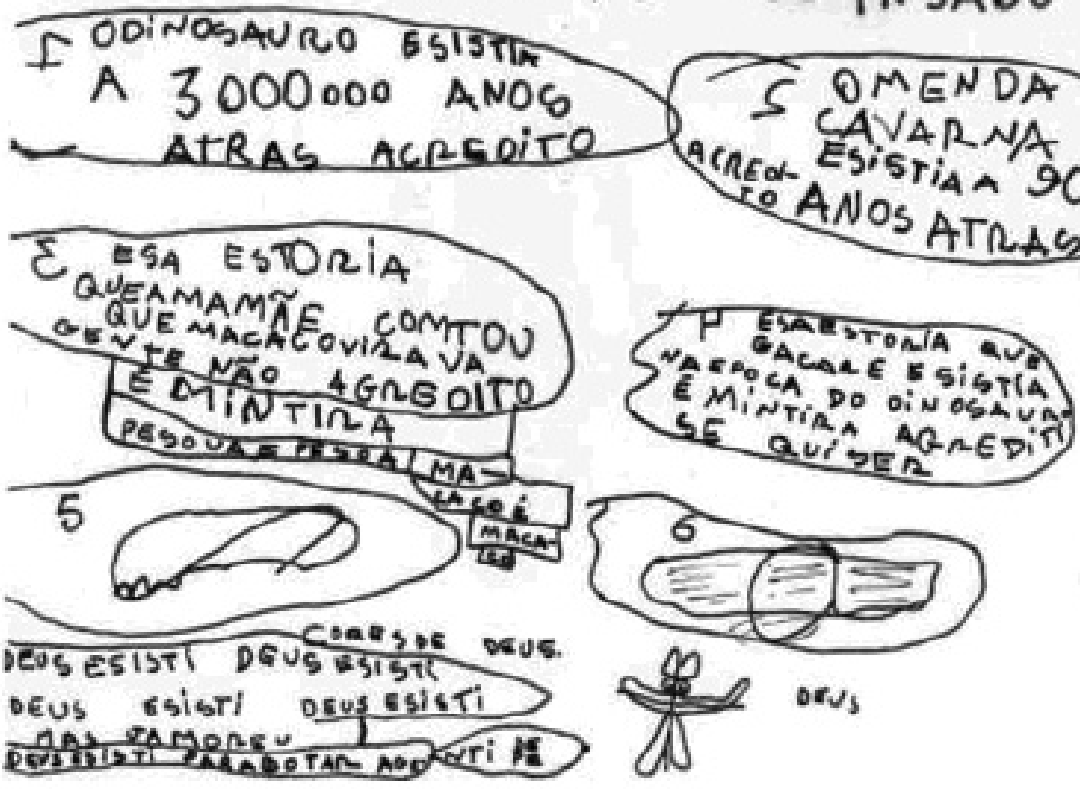

Digitação do texto de acordo com as convençóes numéricas e ortográficas:

\begin{tabular}{|ll|ll|}
\hline 1 & $\begin{array}{l}\text { O DINOSSAURO EXISTIA HÁ } 3000000 \\
\text { ANOS ATRÁS ACREDITO. }\end{array}$ & $\begin{array}{l}\text { O HOMEM DA CAVERNA EXISTIA HÁ } 900000 \\
\text { ANOS ATRÁS ACREDITO. }\end{array}$ \\
\hline 3 & $\begin{array}{l}\text { ESSA ESTÓRIA QUE A MAMÃE CON- } \\
\text { TOU QUE MACACO VIRAVA GENTE } \\
\text { NÃO ACREDITO É MENTIRA PESSOA } \\
\text { É PESSOA MACACO É MACACO. }\end{array}$ & $\begin{array}{l}\text { ESSA ESTÓRIA QUE JACARÉ EXISTIA NA ÉPO- } \\
\text { CA DO DINOSSAURO É MENTIRA ACREDITE } \\
\text { SE QUISER. }\end{array}$ \\
\hline 5 & UM DESENHO & 6 & UM DESENHO \\
\hline $\begin{array}{l}\text { DEUS EXISTE DEUS EXISTE DEUS EXISTE } \\
\text { DEUS EXISTE MAS JÁ MORREU DEUS EXIS- } \\
\text { TE PARA BOTAR A GENTE DE PÉ. }\end{array}$ & $\begin{array}{l}\text { UM DESENHO, ASSEMELHADO A JESUS CRISTO } \\
\text { LADOZ, COM A PALAVRA DEUS ESCRITA AO }\end{array}$ \\
\hline
\end{tabular}

A observação geral do texto nos indica o grande conhecimento que Maria, aos 5 anos, possui sobre a escrita. Um primeiro aspecto que destacamos diz respeito à organização e diagramação do texto no papel e os modos de registro utilizados. A menina escreve convencionalmente, de cima para baixo, da esquerda para a direita, e utiliza o espaço do papel em duas colunas. Para distinguir as estórias que elabora, 
utiliza numerais, ordenando-as como partes do texto. Os caracteres numéricos, entretanto, parecem não possuir ainda força semântica que dê garantia à criança de que a ordem das partes do texto será compreendida pelo leitor. A menina desenha entáo caixas onde insere as partes do texto. As caixas parecem ter sido feitas antes da escrita, já que as de número 3 e 7 , não suficientes para o tamanho do texto, são ampliadas para sua finalização.

A criança organiza o texto em sete caixas; somente a última não é numerada. As caixas de 1 a 4 acolhem partes do texto; nas caixas 5 e 6 não há texto verbal, há imagens desenhadas - serão estórias desenhadas? Na última caixa, Maria repete quatro vezes a frase Deus existe para em seguida dar continuidade ao texto. No original, cada frase repetida é escrita com uma cor diferente, justificando o quase título dessa caixa: Cores de Deus.

Observando o texto como um todo, destacam-se registros de diferentes naturezas simbólicas: o desenho, a escrita alfabética e a escrita ideogramática do sistema de numeração. Cada registro desses representa o mundo de diferentes modos, tendo o grafismo como ponto comum. A natureza pictográfica do desenho convive com as naturezas alfabética e ideogramática, da escrita e do sistema de numeração, respectivamente, no modo como Maria responde à proposta da professora. O sistema alfabético representando primariamente os sons da língua e o de numeração, representando o conceito, a ideia, de cada numeral.

O desenho cumpre distintas funçóes na produção textual da menina: a) função delimitadora das partes do texto, em sete caixas; b) função textual, nas caixas 5 e 6; e c) função de ilustração da parte do texto que consta na sétima caixa. Os números, por sua vez, apresentam valor de ordenação, quando organizam as partes do texto, e de espaço de tempo/quantidade, quando definem o tempo passado: " $a$ 3.000.000 atras" e "a 900.000 anos atrás". Cabe destacar que, no eixo horizontal, a orientação da escrita do sistema numérico é diferente daquela do sistema alfabético: aquele se organiza da direita para a esquerda. Essa pode ser uma hipótese para a escrita invertida dos numerais de 1 a 4 : estáo desenhados no sentido do desenho das letras do alfabeto bastão que Maria utiliza, voltados para a direita. O número 5, no entanto, é grafado corretamente. Se observarmos a escrita do 3 no número 3.000.000, na caixa 1 , verificamos sua escrita correta. Pode ser que no encontro com os zeros tenha se tornado mais distinta a escrita do numeral 3 voltada para a esquerda.

A escrita do texto verbal de Maria é realizada alfabeticamente. Alguns poucos erros ortográficos são encontrados, de acordo com a fase inicial de aprendizagem da escrita. São exemplos de problemas: a representação do fonema /s/, em passado, 
dinossauro, essa, e do fonema/z/, em existiu; a regra de uso do m e do n, antes de bilabiais, na palavra contou; a redução do som do E átono, em mentira, existe e gente, entre outros. Chama-nos a atenção, entretanto, a escrita da expressão de pé, na última parte do texto. A menina organiza a escrita das duas palavras orientada pelo significado da expressão, verticalmente. Por que uma menina que escreve tão bem e desembaraçadamente constrói essa escrita-desenho? Ela escreveu e desenhou? A escrita é para ver e ler?

Do ponto de vista mais estritamente discursivo, Maria encaminha o título do texto como se fosse relatar Estórias do passado, mas o que faz é se reportar a estórias ouvidas, destacando peculiaridades. Elabora nas caixas 1 e 2 duas asserçóes (O dinossauro existia há 3.000.000 anos atrás e $\mathrm{O}$ homem da caverna existia há 900.000 anos atrás,) emitindo seu parecer sobre o enunciado: acredito. Nas caixas 3 e 4, a menina começa o texto pondo em xeque, modalizando, o que escreverá em seguida (Essa estória que...), concluindo com náo acredito (caixa 3) e acredite se quiser (caixa 4). A intencionalidade da autora do discurso a leva, gradualmente, à seleção de construçóes composicionais que vão definindo o estilo do gênero. A sétima caixa apresenta algo que não parece questionável para a menina, como as partes anteriores: Deus existe. Isso talvez explique a ausência de numeração na caixa. A crença que Maria expóe na sétima caixa é afirmada quatro vezes. A repetição pode ser interpretada como uma estratégia de convencimento voltada para o leitor, o outro.

O contraponto que se estabelece com a utilização do encadeador mas (mas já morreu), na sequência, deve ter sido realizado em relaçáo aos seres citados anteriormente no texto, que já existiram, mas não existem mais, o dinossauro e o homem da caverna, diferentemente de Deus que continua existindo. A existência de Deus é argumentada no tempo presente, embora ele já tenha morrido, como ela diz. A argumentação ganha mais força quando Maria define a importância da existência de Deus: "para botar a gente de pé". A menina conclui o texto com o desenho que lembra Jesus Cristo na cruz, imagem-símbolo para a população cristã. $\mathrm{O}$ acento avaliativo, marcado de modo enfático em toda a construção textual, se destaca ao final da enunciação como mais uma estratégia semiótica da produção do discurso de Maria.

Outro aspecto a destacar no discurso escrito da criança é o movimento em direção ao outro, ao leitor. Trata-se de um texto elaborado por uma criança que conhece a textualidade da linguagem para ser escrita, e não falada. Ela sabe também de algum modo que as possibilidades de dizer se dão no contexto de relaçôes de força, de poder, e mergulhada no exterior, no que aprendeu, traz do interior de seu mundo, por escrito, sua compreensão ativa responsiva do que se destacou 
com a experiência de participar do projeto pedagógico. Na perspectiva do debate que se trava no texto, por meio de palavras alheias (de sua mãe, por exemplo) e com palavras alheias, depreendem-se as posiçóes da Ciência e da Religião, além de uma menina que procura significar a realidade a partir de suas reflexóes e de seus conhecimentos possíveis naquele momento.

O próprio modo como Maria cria as circunstâncias da organização do texto, em função de acreditar e não acreditar, estabelece indícios de suas possibilidades de conceber a realidade. É possível para Maria acreditar que o dinossauro e o homem da caverna tenham existido - mas não existam mais. Acreditar, entretanto, na transformação do macaco em ser humano, quando ela os conhece tâo separados e diferentes, parece ser muito complexo. Assim como o jacaré, que existe hoje, também ter existido há muitos anos atrás se mostra problemático - acredite se quiser. Ao mesmo tempo, contudo, é capaz de acreditar em Deus acima de qualquer outra reflexão, verdade que deve ter sido apropriada como palavra de autoridade, no fluxo da comunicaçáo verbal, no processo de se constituir como sujeito social, por meio da linguagem, ou seja, como valor de seu grupo social e familiar primário e possivelmente reforçado na escola católica.

\section{DISCUSSÃO DOS RESULTADOS, CONCLUSÓES E IMPLICAÇÓES PEDAGÓGICAS}

O texto elaborado por Maria afirma nossa hipótese de trabalho de que no processo de aprender a escrever as crianças se utilizam dos conhecimentos de variadas naturezas que já possuem, para produzir seu discurso. Tais conhecimentos estão relacionados a suas constituiçóes como sujeitos sociais por meio da construçáo de sistemas de referência que vão sendo organizados como linguagem e incluem diferentes formas de representação do mundo, ou seja, amplamente semiotizados.

$\mathrm{Na}$ aprendizagem da escrita, especificamente, ao serem desafiadas a escrever e tendo espaço para ousar, as crianças valem-se do universo semiótico em construção para definir estratégias para a elaboração textual, ao mesmo tempo em que se abrem para novas possibilidades discursivas.

$\mathrm{Na}$ análise que fizemos do texto de Maria, observamos como diferentes sistemas representacionais convivem em seu esforço para significar com a escrita. Sistemas orientados por princípios organizacionais distintos são utilizados com funções variadas, e por vezes apresentam instabilidades no uso da mesma função. Os diferentes signos são orientados em função do interlocutor, do auditório social, daí as preocupaçôes da menina com a organização da sequência do texto. $\mathrm{Na}$ aná- 
lise, sobressai a seleção de palavras dos enunciados de Maria realizada a partir das intençóes que presidem o seu todo e na perspectiva da tensão interna que existe em qualquer signo, como diz Bakhtin. Linguagens sociais diversas se evidenciam no texto, mostrando conhecimentos, mas apontando também a dialética interna do signo, o conflito de significados, já observada por Maria, o que a leva a fortalecer a argumentação no que concebe como palavra de autoridade.

No contexto de produçáo do texto, marcadamente híbrido, destaca-se o modo vertical como escreve, por exemplo, a expressão de pé, cruzando orientaçóes de sistemas diversos. Esse dado indicia a complexidade do processo de aprendizagem e a inteligência da criança que procura dar conta de um sem-número de questôes envolvidas na produção textual escrita. O texto é para ler e para ver; lemos o que vemos e vemos o que lemos. No processo de elaborar o texto novas situaçóes aparecem demandando a formação de novos conhecimentos. Estratégias para solucionar os impasses cognitivos se definem no processo, podendo resultar em construçóes híbridas como a escrita da expressão em pé, mesmo no texto de Maria, que já têm uma compreensão avançada dos princípios da escrita alfabética.

Entendemos que todos os aspectos ressaltados na análise realizada compóem o sentido do texto de Maria, integrando, portanto, o plano discursivo. Aqui foram trabalhados separadamente por uma questáo de método, para compreender o movimento de construção de sentido como um todo. A forma de organização espacial do texto no papel e o paralelismo criado pelas partes do texto, por exemplo, apresentam modos de apreensão do conhecimento/linguagem pela menina.

Compreendemos que o fato de o texto analisado ter sido gerado no contexto final de desenvolvimento de um projeto pedagógico tem um relevante significado pedagógico. Projetos pedagógicos, em geral, envolvem o coletivo de crianças em torno de um tema, definindo questóes de interesse para serem investigadas, e mobilizando atividades que incluem acesso a materiais e linguagens diversos, contemplando de modo expressivo a oralidade, a escrita e a leitura. Assim, alguns aspectos merecem destaque e podem ter interferido na produçáo textual de Maria: a) um processo de ensino-aprendizagem planejado e organizado, de modo sistematizado; b) um caminho coletivo de construção de conhecimento; e c) um trabalho em que atividades orais e escritas, mediadas por leituras de diferentes materiais escritos, envolvendo diferentes formas de expressão. Esses três aspectos interligados criam oportunidades para as crianças de participação, interação e reflexão em eventos contextualizados pela cultura escrita, junto com múltiplos sistemas de representação da realidade.

O processo de alfabetização, focalizado aqui na perspectiva da produção de textos socialmente legitimados, é um lugar de tensão, de regularidades 
e irregularidades, de estabilidades e instabilidades. Espaço de construção e transformação do conhecimento em que muitos aspectos importantes dos processos das crianças, antes considerados marginais, podem ser entendidos como constituintes dos sentidos da escrita infantil. Outro aspecto a destacar, ainda hoje pouco levado em conta em práticas pedagógicas e também em pesquisas, é que as crianças são pessoas capazes de aprender complexamente.

\section{REFERÊNCIAS}

Abaurre MBM. Os estudos linguísticos e a aquisição da escrita. In: Castro MFP, editora. O método e o dado no estudo da linguagem. Campinas: Editora da Unicamp; 1996. p. 39-58.

Amorim M. Alteridade e formas de saber. $3^{\text {a }}$ Conferência de pesquisa sócio-cultural; 2000; Campinas, Brasil. Campinas, SP: Unicamp; 2000. p. 9.

Bakhtin M. Questóes de literatura e de estética: a teoria do romance. 5a. ed. Aurora F. Bernardini, José P. Jr., Augusto G. Jr., Helena S. Nazário e Homero F. de Andrade, tradutores. São Paulo: Hucitec; 1998.

Brait B. Análise e teoria do discurso. In Brait B, editora. Bakhtin: outros conceitos-chave. São Paulo: Contexto; 2006. p. 9-31.

Cagliari LC. A escrita no século XXI (ou talvez além disso). [citado 10 jul. 2008]. Disponível em http://www.unicamp.br/iel/memoria/Ensaios; 2007.

Calvino I. Seis propostas para o próximo milênio. Ivo Barroso, tradutor. São Paulo: Companhia das Letras; 1990. p. 146.

Corrêa MCC. A constituição do vocábulo formal no texto escrito. In Amorim M, organizadora. Psicologia escolar: artigos e estudos. Rio de Janeiro: Editora da UFRJ; 1990. p. 27-37.

Ginzburg C. Raízes de um paradigma indiciário. In Ginzburg C. Mitos, emblemas, sinais. Morfologia e História. São Paulo: Companhia das Letras; 1989. p. 143-179.

Goulart CMA. Cultura escrita e escola: letrar alfabetizando. In Marinho M, Carvalho GT, organizadores. Cultura escrita e letramento. Belo Horizonte: Editora UFMG; 2010. p. $438-456$.

Goulart CMA. Alfabetização e letramento: os processos e o lugar da literatura. In: Paiva A, Martins A, Paulino G, Correa H, Versiani Z, organizadores. Literatura: saberes em movimento. Belo Horizonte: CEALE/Autêntica; 2007. p. 57-68. 
Goulart CMA, Garcia IHM, Souza ML, Gonçalves AV et alii. Processos de letrar e ser letrado na infância: modos de letrar e ser letrado na família e no espaço educativo formal. Relatório final de pesquisa. Programa de Pós-Graduação em Educação, UFF/CNPq; 2005. Relatório técnico.

Halliday MAK. The language of early childhood. Jonathan Webster, editor. Continuum; 2004. 415 p.

Halliday MAK. Learning how to mean. Explorations in the development of language. London: Edward Arnold; 1975. 161 p.

Pacheco CMG. Um estudo exploratório de aspectos do processo de produção de textos escritos por crianças de 7 anos [dissertação]. Rio de Janeiro: Pontifícia Universidade Católica, Departamento de Letras; 1992.

Pacheco CMG. Era uma vez três cabritinhos: a gênese do processo de produção de textos escritos [tese]. Rio de Janeiro: Pontifícia Universidade Católica, Departamento de Letras; 1997.

Soares MB. A escolarização da leitura literária. In: Evangelista A, Brandão H, Machado $\mathrm{ZV}$, editoras. A escolarização da leitura literária: o jogo do livro infantil e juvenil. Belo Horizonte: Autêntica; 1999. p. 5-23.

Soares MB. Letramento: um tema em três gêneros. Belo Horizonte: Autêntica; 1998. 125 p.

Sobral A. Elementos sobre a formação de gêneros discursivos: a fase "parasitária" de uma vertente do gênero de auto-ajuda [tese]. São Paulo: Pontifícia Universidade Católica, Departamento de Letras; 2007.

Street BV. Abordagens alternativas ao letramento e desenvolvimento. Teleconferência UNESCO/Brasil sobre Letramento e diversidade, realizada em outubro de 2003. Disponível em <http://www.telecongresso.sesi.org.br>

Street BV. Literacy in theory and practice. Cambridge: University Press; 1984.

Recebido em: 01/12/2015

Aceito em: 09/12/2015

Goulart, C.M.A. O processo de alfabetização e a produção do sentido no discurso escrito... 